\title{
Ultrasound image attributes of bovine ovarian follicles and endocrine and functional correlates
}

\author{
J. Singh ${ }^{1 *}$, R. A. Pierson ${ }^{2}$ and G. P. Adams ${ }^{1 \dagger}$ \\ ${ }^{1}$ Department of Veterinary Anatomy, Western College of Veterinary Medicine, and ${ }^{2}$ Department of \\ Obstetrics and Gynecology, College of Medicine, University of Saskatchewan, Saskatoon, \\ Saskatchewan S7N 5B4, Canada
}

\begin{abstract}
Heifers were studied to determine whether computer-assisted quantitative echotexture analysis of ultrasound images reflect functional and endocrine characteristics of dominant and subordinate follicles at specific stages of development. Heifers were examined using transrectal ultrasonography each day until ovariectomy on day $3(n=8)$ and day $6(n=9)$ of wave 1 , day 1 of wave $2(n=7)$, or after onset of pro-oestrus $\geq 17$ days after ovulation $(n=8)$ to obtain growing, early-static, late-static and regressing dominant follicles of wave 1 , subordinate follicles, preselection follicles and preovulatory dominant follicles. Ultrasound images of the follicles were obtained in vitro and analysed using custom-developed computer algorithms. Mean pixel (picture element) values (grey-scale: black $=0$, white $=255)$ for the follicle wall and stroma increased $(P<0.05)$ progressively from the growing to the regressing phases of the dominant follicle of wave 1 . The antrum and wall of subordinate follicles had higher $(P<0.05)$ mean pixel values than that of the corresponding dominant follicles. Pixel heterogeneity (a measure of variation of grey-scale values of pixels) of images of the follicle antrum and wall increased $(P<0.05)$ progressively during the early-static to regressing phases. A progressive increase $(P<0.05)$ in the slope of the regression line of pixel values for the follicle wall was detected from the growing to the regressing phases of the dominant follicle of wave 1 . The regression line of the wall of the preovulatory dominant follicle had the lowest $(P<0.05)$ slope. Oestradiol concentration in the follicular fluid decreased $(P<0.05)$ from the growing to the late-static phase, while a marked decrease $(P<0.05)$ in the androstenedione concentration was recorded between the growing and the early-static phases of the dominant follicle. Progesterone content did not increase until follicles were in the final stages of regression. Pixel heterogeneity of the antrum and wall, and the slope of the follicle wall regression line were negatively correlated $(P<0.001)$ with oestradiol and the oestradiol:progesterone ratio in follicular fluid. The results of this study support the hypothesis that echotexture characteristics of ultrasound images of the follicle antrum and wall are correlated with the functional and endocrine status of a follicle.
\end{abstract}

\section{Introduction}

The mature ovarian follicle is a complex structure composed of the granulosa and theca interna layers which co-operate in nutrition of the ovum and production of steroid hormones and numerous peptide factors. Earlier studies (Choudary et al., 1968) indicated that, at any given time during the oestrous cycle, $77 \%$ of bovine follicles are atretic and small follicles enter the final phase of growth continuously throughout the oestrous cycle. Steroid analysis of bovine follicular fluid indicates that a single

*Present address: Department of Veterinary Anatomy and Histology, College of Veterinary Science, Punjab Agricultural University, Ludhiana - 141004 , Punjab, India.

${ }^{\dagger}$ Correspondence.

Received 27 March 1997 large 'oestrogen-active', non-ovulatory follicle develops between 3 and 7 days after oestrus (Ireland and Roche, 1983). The growth and atresia of individual antral follicles have been monitored more critically using sequential ultrasonography, and it has been established that growth of follicles $\geq 4 \mathrm{~mm}$ takes place in two or three waves during the oestrous cycle (Pierson and Ginther, 1986, 1987a, 1988; Savio et al., 1988; Sirois and Fortune, 1988; Knopf et al., 1989; Ginther et al., $1989 a, b)$. During an anovulatory wave, the development of each follicle has been subdivided into growing (increasing diameter), static (no change in diameter) and regressing (decreasing diameter) phases (Ginther et al., 1989b). Consistent temporal relationships between follicle phases, wave dynamics and systemic gonadotrophin concentrations (Ginther et al., 1989c; Adams et al., 1992, 1993a), as well as the ability of 
follicles to ovulate in response to prostaglandin-induced luteolysis (Kastelic et al., 1990; Savio et al., 1990; Fortune et al., 1991), have led to the conclusion that follicle development is a well controlled, tightly co-ordinated phenomenon. Ultrasonographically classified phases have also been shown to be correlated closely with the ability of follicles to produce steroid and protein hormones (oestrogen:progesterone and oestradiol: androstenedione ratios, $\alpha$ - and dimeric-inhibin concentrations, IGF-binding proteins) indicative of follicular health (Badinga et al., 1992; Guilbault et al., 1993; Price et al., 1995; Carriere et al., 1996; Stewart et al., 1996; Sunderland et al., 1996).

Grey-scale densitometry has been used for quantitative analysis in a number of different fields such as gel electrophoresis, microspectrophotometry and immunohistochemistry (Sternberger and Sternberger, 1986; Fritz et al., 1989, 1992; Renucci et al., 1991; Ferrandi et al., 1993). However, to develop image analysis as a diagnostic tool for evaluating ultrasound images, an objective procedure for grey-scale evaluation is needed. We investigated the echotexture attributes of the bovine corpus luteum using a computer-assisted image analysis procedure (Singh et al., 1997), and results supported the hypothesis that ultrasound images reflect luteal structure and progesterone production. The present study is an extension of this research and is focused on ultrasound image attributes of bovine ovarian follicles.

The present study was designed to evaluate the changes in echotexture of ultrasound images of ovarian follicles and to determine whether quantitative changes in echotexture components of images of dominant and subordinate follicles at different stages of development reflect their functional characteristics. The specific hypothesis under test was that echotexture characteristics of high-resolution ultrasound images of the follicle antrum and wall are correlated with functional and endocrine status, as determined by serial ultrasonography and measurement of the steroid hormone content of follicular fluid, respectively.

\section{Materials and Methods}

\section{Animal grouping and ultrasonography}

The present study was conducted on 16- to 18-month-old mature nulliparous crossbred beef heifers (primarily Hereford). Heifers $(n=32)$ were maintained in a single corral and fed to gain approximately $1.3 \mathrm{~kg}$ day $^{-1}$. Ovarian follicle development was monitored by transrectal ultrasonography each day using a $7.5 \mathrm{MHz}$ linear-array transducer (Aloka Co. Ltd, Tokyo). Ultrasound examinations commenced at least 2 days before ovulation preceding the oestrous cycle under study and continued until the day of ovariectomy to monitor the development of follicles $\geq 4 \mathrm{~mm}$ in diameter. The topographic location and diameter of individually identified follicles and corpora lutea were recorded each day (Knopf et al., 1989). The day of wave emergence (day 0 ) was determined retrospectively and defined as the day on which the dominant follicle of a wave was first detected at a diameter of $4-5 \mathrm{~mm}$ (Ginther et al., 1989a; Adams and Pierson, 1995). The dominant follicle was defined as the largest follicle of a wave, and subordinate follicles were defined as those that appeared to originate from the same pool of follicles (Ginther et al., 1989a; Knopf et al., 1989). As the heifers ovulated, they were designated randomly to be ovariectomized on day 3 of wave 1 (D3WI, $n=8$ ), day 6 of wave I (D6W1, $n=9$ ), day 1 of wave 2 (D1W2; $n=1$ on day $8, n=2$ on day $9, n=1$ on day $10, n=1$ on day $11, n=1$ on day 12 after ovulation), or in the immediate preovulatory period $\geq 17$ days after ovulation $(\mathrm{D} \geq 17 ; n=1$ on day 17 , $n=3$ on day $18, n=3$ on day 19, $n=1$ on day 20 after ovulation). Heifers in the $\mathrm{D} \geq 17$ group were ovariectomized 1 day after detection of pro-oestrus. Pro-oestrus was defined as the day when any three of four oestrus-like characteristics high uterine tone, oedematous echotexture, intrauterine fluid collection and mucous discharge - were detected (Pierson and Ginther, 1987b). Days of ovariectomy were selected on the basis of previous studies (Adams et al., 1992; Ginther et al., 1989a) to represent growing (D3W1), early-static (D6W1), late-static (DIW2) and regressing ( $\geq 17$ ) phases of the dominant follicle of wave I (Fig. 1), while under the influence of declining, minimal and maximal concentrations of circulating FSH, respectively. The design of the experiment also allowed collection of subordinate follicles of wave 1 and the ovulatory wave, preselection follicles of wave 2, and preovulatory dominant follicles (Fig. 1).

\section{Ovariectomy, ultrasound imaging and follicular fluid collection}

Heifers were ovariectomized on the designated day via colpotomy (Hudson 1986) in the standing position, under caudal epidural anaesthesia using $2 \%(\mathrm{w} / \mathrm{v})$ lidocaine $\mathrm{HCl}$ with $0.001 \%(\mathrm{w} / \mathrm{v})$ adrenaline. Clenbuterol $\left(0.6 \mu \mathrm{g} \mathrm{kg}^{-1}\right.$ bodyweight; Ventipulmin, Boehringer Ingelheim Ltd, Ontario) was given intravenously $10 \mathrm{~min}$ before colpotomy to induce relaxation of the uterine and broad ligament musculature (Hassat and Sloss, 1984). After manual compression of the mesovarium with a lidocaine-soaked gauze, both ovaries were removed through a single incision in the dorsolateral aspect of the vaginal fornix using a chain écraseur. Heifers were treated postoperatively with procaine penicillin $G$ for 4 days.

After ovariectomy, the ovaries were placed immediately in ice-cold PBS $\left(0.1\right.$ mol phosphate buffer $l^{-1}, 0.9 \%(\mathrm{w} / \mathrm{v})$ sodium chloride, $\mathrm{pH} 7.2-7.4)$ and transported to the laboratory within $45 \mathrm{~min}$ of ovariectomy. The ovaries were placed in a degassed PBS bath and imaged using a broad-band (5-9 MHz), convexarray, ultrasound transducer (ATL Mark 9 HDI ultrasound machine; Advanced Technology Laboratories, Bothell, WA). Serial ultrasound images of both ovaries were digitally acquired at $0.5 \mathrm{~mm}$ increments directly from the ultrasound machine to a computer at a resolution of $640 \times 480$ pixels and 256 shades of grey $(0=$ absolute black; $255=$ absolute white). Images from all follicles were digitized at standardized settings. Follicular fluid was aspirated from individually identified follicles, centrifuged at 2500 r.p.m. for $15 \mathrm{~min}$, and frozen at $-20^{\circ} \mathrm{C}$ until assay.

On the basis of daily ultrasound records, follicles were identified as the dominant, largest subordinate and second largest subordinate on the day of ovariectomy. Only those dominant and largest subordinate follicles that were individually identified were collected and analysed. On the day of ovariectomy, if the second largest subordinate follicle could not be distinguished from other subordinates (that is, if it had a 
similar diameter; $D 6 W 1, D \geq 17$ ), one was chosen arbitrarily for image analysis and included in the second largest subordinate category. Hence, the second largest subordinate category included follicles that were individually identified as well as those that could not be individually identified. In D6W1 and $\mathrm{D} \geq 17$ groups, the fluid from the three largest follicles other than the dominant and largest subordinate was pooled (within animal) to provide sufficient volumes for steroid assays, and categorized as the second largest subordinate follicle. In the DIW2 group, the three largest follicles of wave 2 were collected to represent preselection follicles because dominance was not yet apparent. All follicle designations were suffixed with W1, W2 or OvW to identify the first, second or ovulatory wave, respectively.

\section{Radioimmunoassays of follicular fluid}

For all assays, serial dilutions of samples were parallel to their respective standard curves. Oestradiol, androstenedione, and progesterone were measured in the follicular fluid by radioimmunoassay (DPC coat-a-count, Diagnostic Products Corporation, Los Angeles, CA) using the non-extraction procedure validated with standards prepared in charcoal-extracted pooled bovine follicular fluid from ovaries obtained at an abattoir. Each assay was further validated by measuring the concentration of oestradiol, androstenedione or progesterone after adding the known amount of the steroid in the same charcoal-extracted pooled bovine follicular fluid in which standards were prepared. The minimum detection limit of the assay was $5 \mathrm{pg} \mathrm{ml}^{-1}$ for oestradiol, $0.15 \mathrm{ng} \mathrm{m}^{-1}$ for androstenedione, and $0.1 \mathrm{ng} \mathrm{ml}^{-1}$ for progesterone. For each hormone, all follicular fluid samples were analysed in a single assay. Intra-assay coefficients of variation for high- and lowreference follicular fluid, respectively, were $4.6 \%$ and $7.5 \%$ for oestradiol, $7.5 \%$ and $7.8 \%$ for androstenedione, and $3.5 \%$ and $5.0 \%$ for progesterone. The hormone concentrations were adjusted to amounts within the measuring range of the assay by diluting follicular fluid samples 1:5 to 1:1000 for oestradiol, 1:10 to 1:100 for androstenedione, and 1:10 for progesterone, using the same charcoal-extracted pooled bovine follicular fluid in which the standards were prepared.

\section{Quantitative echotexture analysis of ultrasound images}

Analysis of ultrasound images was performed using a series of custom-developed computer algorithms optimized for ultrasonography (SYNERGYNE Version $2.8^{*}$ Saskatoon, Saskatchewan) on a Sun Sparc Station (Sun Microsystems, Mt View, CA) computer (Pierson and Adams, 1995; Singh et al., 1997). From each follicle, three images were selected at $1 / 3,1 / 2$ (maximum diameter) and $2 / 3$ distance from one edge of the follicle. Image analysis was performed by an individual to whom individual image identities were not disclosed.

Spot analysis of follicle antrum. Quantitative echotexture analysis of the follicular antrum was performed on the basis of measurement of pixel values (that is, grey-scale values of individual picture elements ranging from 0 to 255). The antral region of each follicle image was divided into four quadrants (Fig. 2) and the pixel value and pixel heterogeneity from each region were measured by a computer-generated spot meter encompassing approximately $20 \%$ of each quadrant (Pierson and Adams, 1995). The pixel value was the mean of grey-scale values of all pixels falling under the measuring spot, and pixel heterogeneity was the standard deviation of grey-scale values of all the pixels falling under the measuring spot. Maximum and minimum pixel values were also measured from the grey-scale bar of each image to permit normalization of measurements among images (Singh et al., 1997). Normalization of pixel values involved re-scaling the values on a scale of 0 (black, or minimum value on grey-scale bar) to 255 (white, or maximum value on grey-scale bar) using the formula:

$$
\begin{aligned}
& \text { Adjusted } P V=(\text { Actual } P V-\min P V G S B) \\
& \times(255 /(\max P V G S B-\min P V G S B))
\end{aligned}
$$

where $P V=$ pixel value; $\min P V G S B=$ minimum pixel value of grey-scale bar and maxPVGSB = maximum pixel value of grey-scale bar. The mean pixel value and the pixel heterogeneity of the antrum for each follicle was obtained as an average of 12 measurements (three images per follicle and four regions per image).

Line analysis of the peripheral antrum, follicle wall and stroma. Line analysis was used to measure the grey-scale values of pixels along a straight line (Pierson and Adams, 1995). Evaluation of follicle images by the line-analysis tool (Fig. 2) involved sampling pixel values along a line traversing the follicle wall from the peripheral antrum to the stroma. Enhanced through-transmission and shadowing artifacts were avoided by selecting areas located within the 10 and 2 o'clock positions of the follicles (Kremkau, 1989; Ginther, 1995; Heller and Jehle, 1995). The antrum-wall interface of the follicle was defined as the last pixel after which there was a sequential rise in grey-scale values (Fig. 2). Each pixel of the ultrasound image represented a linear distance of $70.0 \pm 1.1 \mu \mathrm{m}$ of tissue. Fourpixel segments of the line encompassing the peripheral antrum, wall and stroma, respectively, were analysed separately. The antrum-wall interface was used as a reference point to divide the line into the three segments (Fig. 2). On the basis of the morphometric analysis of follicles obtained at identical stages of development (Singh, 1997), the three segments of the line represent the follicle antrum close to the granulosa layer, the granulosa and theca layers, and ovarian stroma, respectively. The follicle wall was analysed at two different locations (that is, at the 10 and 2 o'clock positions of follicle). Mean pixel value (average of grey-scale values) and pixel heterogeneity (standard deviation of the grey-scale values) were recorded separately for the three segments for each of the line analyses. The pixel values along the line were used to obtain the intercept and slope of a regression line of each of the three segments separately (Fig. 2). Mean pixel value, pixel heterogeneity, intercept and slope of the peripheral antrum, wall and stroma of each follicle were obtained by averages of six values (three images per follicle, two lines per image).

\section{Statistical analyses}

All endpoints were analysed by two-factor analysis of variance (follicle type and day of wave). If the probability value 


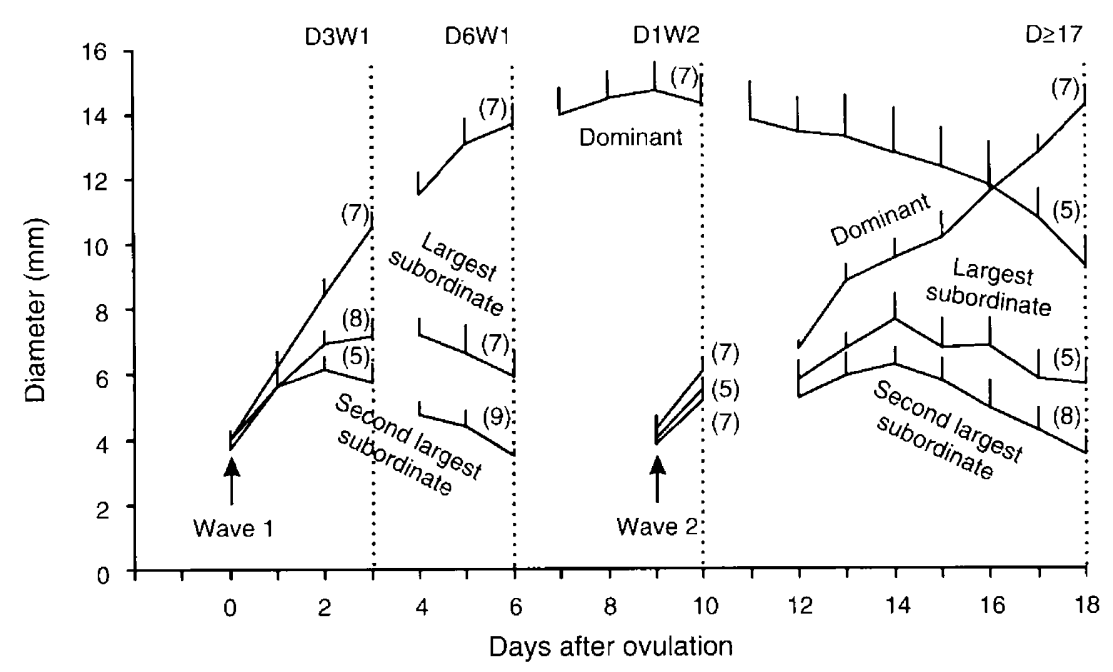

Fig. 1. Diameter profiles (mean \pm SEM) of the dominant, largest subordinate, and second largest subordinate follicles of wave 1 (anovulatory) and wave 2 (ovulatory). The dotted lines indicate the mean days of ovariectomy on day 3 of wave 1 (D3W1), day 6 of wave 1 (D6W1), day 1 of wave 2 (DIW2), and during pro-oestrus $\geq 17$ days after ovulation $(\mathrm{D} \geq 17)$. The numbers in parentheses are the number of follicles of each type collected for each period. Breaks in the profiles indicate that data were included only from those heifers ovariectomized at the end of that segment. For heifers ovariectomized $\geq 17$ days after ovulation, only the diameter profiles of those heifers in which wave 2 was the ovulatory wave are shown. No significant differences were detected for endocrine and echotexture endpoints between the largest and second largest subordinate follicles, so these two categories were merged into a single group for analysis.

for follicle, day or follicle-by-day interaction was $P \leqslant 0.05$, multiple comparisons were made using the least significant difference. Initially, data for all endpoints were analysed for differences among dominant, largest subordinate and second largest subordinate follicles (Fig. 1); however, as no statistical differences were detected between largest and second largest subordinate follicles, the data were re-analysed after combining subordinate follicles into a single group and results are presented as such. Mean pixel value and pixel heterogeneity of spot analysis of the antrum and line-analysis of the antrum were compared using paired Student's $t$ tests. Ultrasound data from the spot and line analyses before and after normalization, and follicles of the ovulatory wave 2 versus ovulatory wave 3 (for the $\mathrm{D} \geq 17$ group) were also compared by Student's $t$ tests. Pearson's correlations between hormone data and ultrasound image attributes were calculated by matching the values of individual follicles without any categorization. Only statistically significant correlations exceeding $r=0.45$ were reported. Results are presented as means \pm SEM.

\section{Results}

The diameter profiles of the follicles under study are presented (Fig. 1). Data are illustrated (Figs 3-6) according to follicle phase; the first four groups (from left to right) represent dominant and subordinate follicles of wave 1 , followed by preselection follicles of wave 2 (collected 1 day after wave emergence) and the follicles of the ovulatory wave after onset of oestrus. Of the seven preovulatory follicles, five came from wave 2 and the remaining two from wave 3; no statistical differences were detected for any endocrine or echotexture endpoint between ovulatory follicles of wave 2 and those of wave 3 , so the data were combined into a single group. For illustrative purposes, diameter profiles of only wave 2 preovulatory follicles have been shown (Fig. 1). Ultrasound image data were analysed both before and after the normalization procedure and results did not differ; however, the values after normalization were used for statistical interpretation and reporting since they account for uncontrolled image drift and better represent relative differences among follicles.

\section{Follicle status}

On the basis of diameter profiles (Fig. 1), all dominant follicles of wave $\mathrm{I}$ were in the growing phase on D3WI, the early-static phase on D6W1, the late-static phase on D1W2, and the regressing phase on $D \geq 17$. Subordinate follicles of wave 1 were in the early-static phase on D3W1 and the regressing phase on D6W1. All preselection follicles of wave 2 on DIW2, and the preovulatory follicles on D $\geq 17$ were in the growing phase. Subordinate follicles of the ovulatory wave were regressing on $\mathrm{D} \geq 17$.

\section{Hormone concentration in follicular fluid}

Oestradiol. Concentrations of oestradiol in dominant follicles were higher $(P<0.001)$ in all phases than that of subordinate follicles, except during the preselection phase (DIW2), when the dominant follicle could not be distinguished from its subordinates (Fig. 3). Maximal concentrations of 
oestradiol in anovulatory dominant follicles of wave 1 occurred during the growing phase (D3W1), and decreased progressively $(P<0.05)$ during the early-static (D6W1), late-static (D1W2), and regressing ( $D \geq 17$ ) phases. Concentrations of oestradiol in the subordinate follicles did not change over time. Concentrations of oestradiol did not exceed 45.0 $\pm 20.1 \mathrm{ng}$ $\mathrm{ml}^{-1}$ for the preselection follicles of wave 2 (DIW2) and $12.9 \pm 11.3 \mathrm{ng} \mathrm{ml}^{-1}$ for the subordinate follicles of wave 1 (D3W1 and D6W1) or the ovulatory wave (D $\geq 17$ ).

Androstenedione. Higher $(P<0.05)$ concentrations were present in the growing dominant follicles of wave 1 (D3W1)
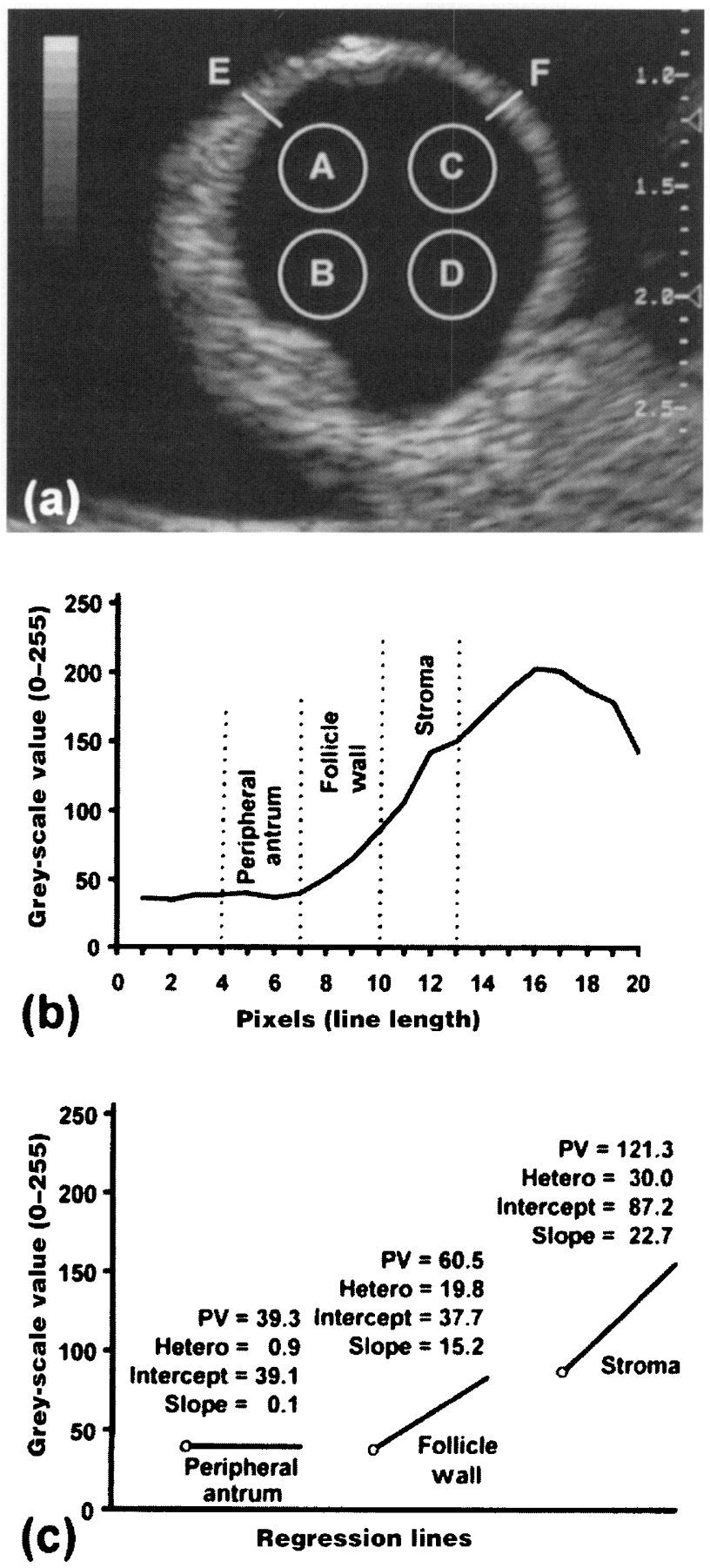

and preovulatory dominant follicles $(D \geq 17)$ than in subordinate follicles. A marked decrease $(P<0.05)$ was detected between the growing (D3W1) and early-static (D6W1) phases of the dominant follicle of wave 1 . The content of androstenedione in the follicular fluid of subordinate follicles did not change over time. Follicular concentrations of androstenedione followed a pattern similar to that of oestradiol $(r=0.77$; $P<0.001)$.

Progesterone. The effects of phase $(P<0.001)$ and follicle type $(P<0.03)$ on progesterone concentration were attributed to higher values during the regressing phase of the dominant (D $\geq 17$ ) and subordinate (D6W1) follicles of wave 1 . Progesterone content was otherwise low.

Hormone ratios. The ratio of oestradiol:androstenedione was higher $(P<0.05)$ in dominant follicles than in subordinate follicles during all phases except the preselection phase (DIW2), when dominant and subordinate follicles were not distinguishable. The highest $(P<0.05)$ ratio of oestradiol:androstenedione was detected in the early-static phase dominant follicle (D6W1). The ratio of oestradiol:progesterone was highly correlated $(r=0.94 ; P<0.001)$ with the oestradiol concentration, but not to progesterone concentration $(r=0.2$; $P>0.06)$. Only the growing dominant follicle of wave 1 (D3WI) and the preovulatory dominant follicle ( $D \geq 17$ ) had an androstenedione:progesterone ratio of $>1$, and were distinct from the subordinate follicles. A marked $(P<0.05)$ decrease in androstenedione:progesterone ratio occurred between the growing (D3W1) and early-static (D6W1) phases of the dominant follicle of wave 1 .

\section{Quantitative echotexture analysis of ultrasound images}

Spot analysis of follicle antrum. The effects of follicle phase $(P<0.001)$ and type $(P<0.002)$ on mean pixel value of the antrum (Fig. 4) were attributed to increasing values during the regressing and preovulatory phases, and higher values in subordinate follicles than in dominant follicles. Heterogeneity of the antrum of the dominant follicle was relatively high at wave emergence (D1W2), decreased $(P<0.05)$ at the time of

Fig. 2. Image analysis of high-resolution ultrasound images of the ovarian follicle (a: scale is in $\mathrm{cm}$ ). Spot analysis of the antrum was performed to measure the pixel (picture element) value and pixel heterogeneity by placing the measuring circle at four different locations $(A, B, C, D)$ over the follicle antrum to cover approximately $20 \%$ of the area in each quadrant. The pixel value was the mean of grey-scale values (black $=0$, white $=255$ ) of all the pixels falling under the measuring circle and pixel heterogeneity was the standard deviation of these values. Line-analysis of the peripheral antrum, follicle wall and stroma was performed by drawing a line at 10 and 2 o'clock positions (E, F) and plotting the grey-scale values of pixels along the line (b). The pixel value graph was divided into three segments (peripheral antrum, follicle wall, stroma) each of which was four pixels in length (approximately $280 \mu \mathrm{m}$ ); the antrum-wall interface was used as a reference point. The pixel value (PV), pixel heterogeneity (Hetero), and the intercept and slope of the regression line (c) of each segment were recorded separately. 

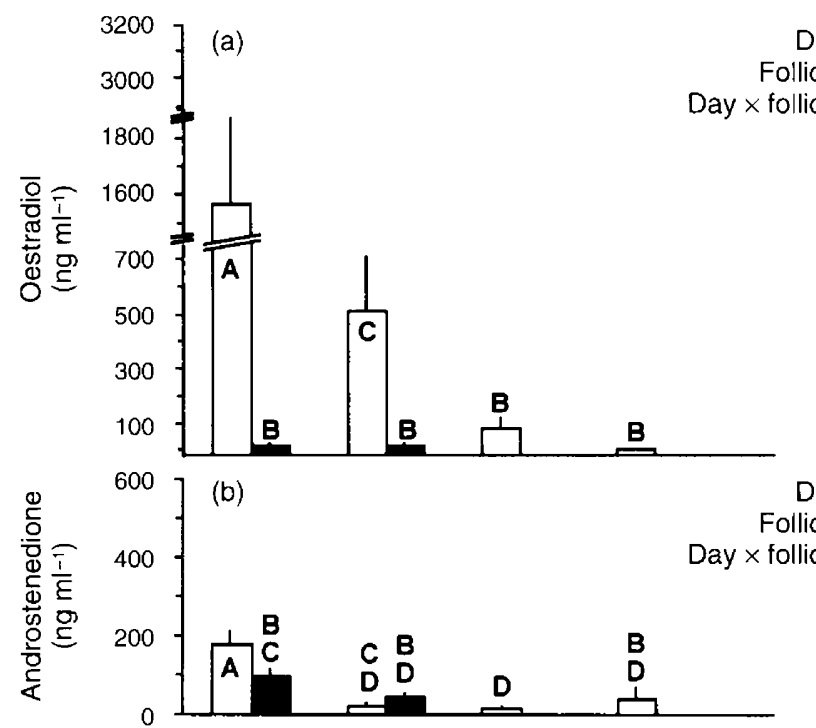

Day $P<0.001$

Follicle $\quad P<0.001$

$P<0.001$

Day $P<0.001$

$P<0.001$

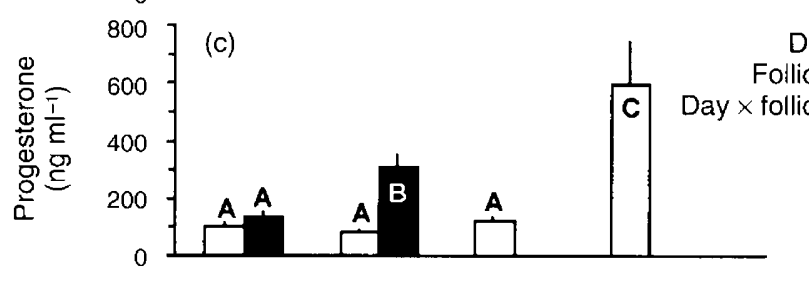

B

Day $P<0.001$

follicle $\quad P<0.034$

NS

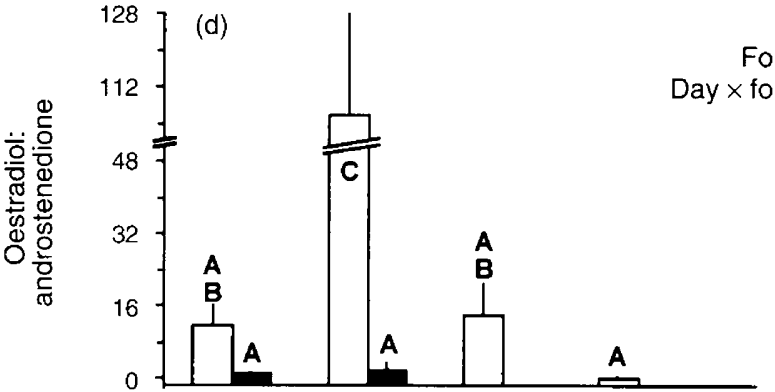

Day $P<0.001$

Follicle $\quad P<0.001$

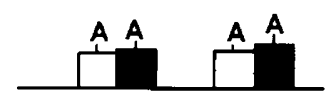

30 (e)

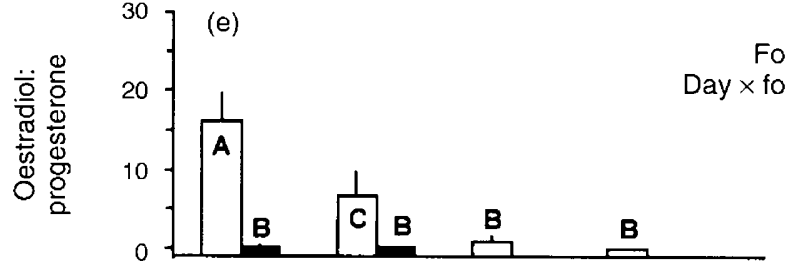

Day $P<0.001$

Follicle

$P<0.001$
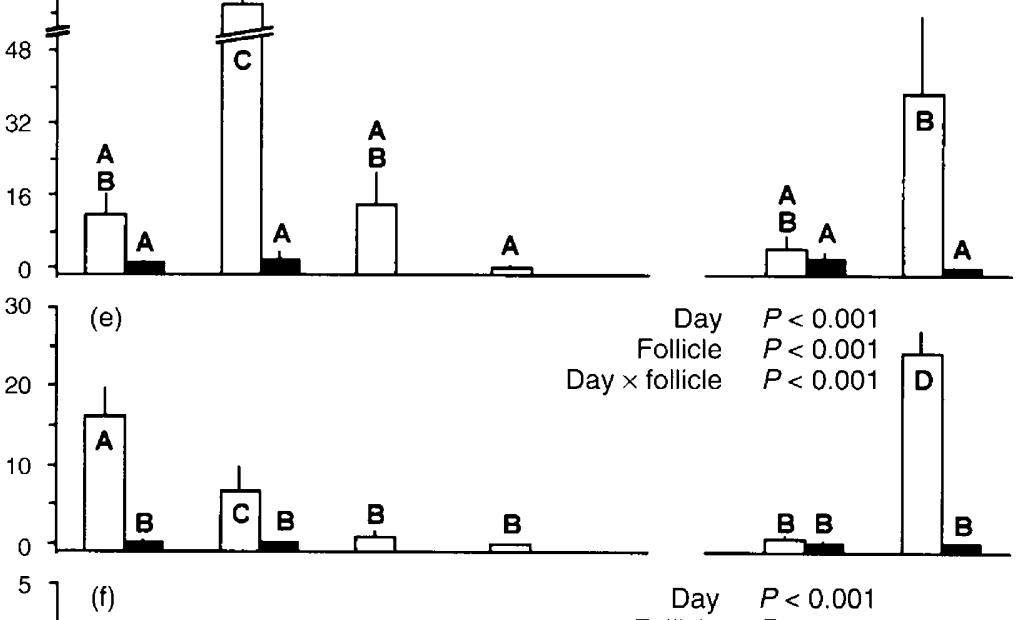

$(\mathrm{f})$

ollicle
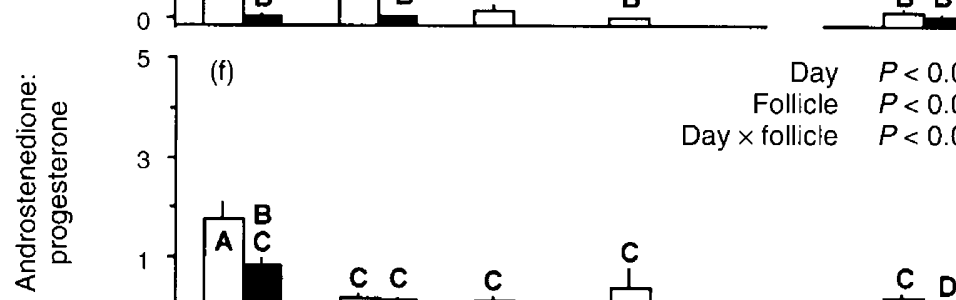

$3-$

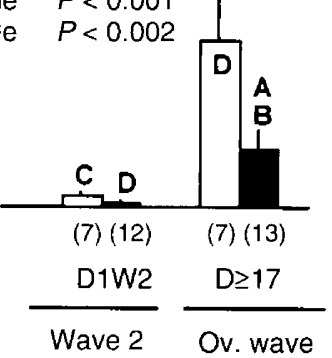

Day:

1

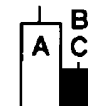

(7) (13)
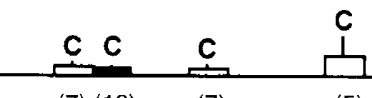

(5)

Follicles of:

Wave 1

Fig. 3. Concentration (mean \pm SEM) of (a) oestradiol, (b) androstenedione and (c) progesterone, and the ratios of (d) oestradiol:androstenedione, (e) oestradiol:progesterone and ( $\mathrm{f}$ ) androstenedione:progesterone in the fluid of $(\square)$ dominant and $(\boldsymbol{\square})$ subordinate follicles at different phases of development (D3W1: day 3 of wave 1; D6W1: day 6 of wave 1; D1W2: day I of wave 2; $\mathrm{D} \geq 17$ : during pro-oestrus $\geq 17$ days after ovulation; $\mathrm{Ov}$. wave: ovulatory wave). Numbers in parentheses below the $x$-axis indicate the number of follicles analysed for each follicle type. Bars with no common letters indicate significantly different values $(P<0.05)$. NS, not significant. 


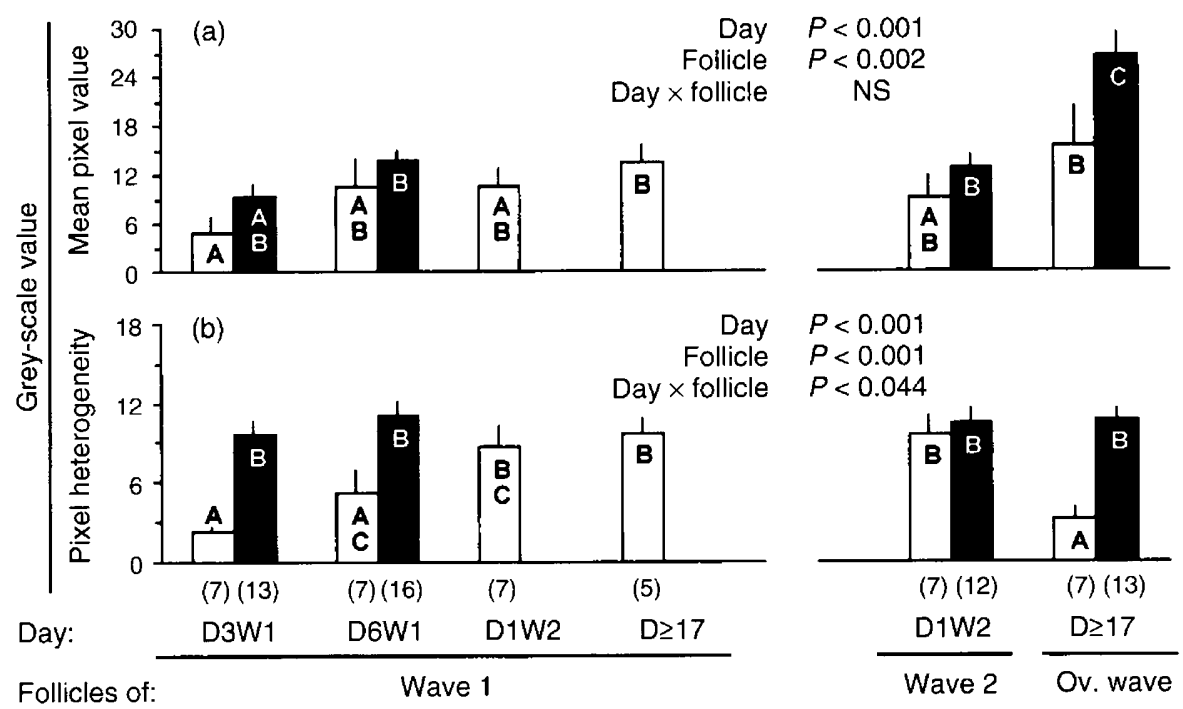

Fig. 4. Mean \pm SEM (a) pixel value and (b) pixel heterogeneity obtained by spot-analysis of the antrum of the dominant $(\square)$ and subordinate $(\square)$ follicles at different stages of wave development (D3W1: day 3 of wave 1; D6W1: day 6 of wave 1; D1W2: day 1 of wave 2; D $\geq 17$ : during pro-oestrus $\geq 17$ days after ovulation; Ov. wave: ovulatory wave). Numbers in parentheses below the $x$-axis indicate the number of follicles analysed for each follicle type. Bars with no common letters indicate significantly different values $(P<0.05)$. NS, not significant.

selection (D3W1), and gradually increased $(P<0.05)$ again during the static and regressing phases. Antral heterogeneity was high and remained unchanged in subordinate follicles.

Line analysis of the follicle wall. Mean pixel value for the peripheral antrum did not differ among days or follicle type, except for the subordinate follicles of the ovulatory wave, in which it was maximal $(P<0.05 ;$ Fig. 5$)$. Changes in mean pixel values and heterogeneity of the follicle wall and stroma followed similar patterns (Fig. 5). The late-static and regressing phases of dominant and subordinate follicles were associated with higher $(P<0.05)$ values than earlier phases. Mean pixel values of the wall and stroma of the regressing subordinates of the ovulatory wave were particularly high $(P<0.05)$. The mean pixel value of the central antrum (assessed by spot analysis) was lower, on average $(P<0.001)$, than that of the peripheral antrum (assessed by line analysis). Similarly, the mean pixel heterogeneity of the central antrum was lower $(P<0.001)$ than that of the peripheral antrum.

The average coefficient of determination for the fitted regression lines ranged from 0.49 to 0.70 for the peripheral antrum, from 0.90 to 0.97 for the follicle wall, and from 0.83 to 0.95 for the stroma. The coefficients of determination were not different $(P>0.5)$ for the three segments. Intercept values of regression lines of the peripheral antrum, follicle wall and stroma were higher $(P<0.05)$ during the regressing phases than during the growing or early-static phases of the dominant and subordinate follicles (Fig. 6). The wall of subordinate follicles of the ovulatory wave had the highest intercept value $(P<0.05)$. A progressive increase $(P<0.05)$ in the slope of the regression line for the follicle wall was detected after the growing phase (D3W1) of dominant follicle of wave 1, with a marked increase between the early-static (D6W1) and latestatic (DIW2) phases. The slope of the regression line of the follicle wall and stroma was lower $(P<0.05)$ for dominant follicles than for the subordinate follicles, except during the preselection phase, and was lowest $(P<0.05)$ for the preovulatory dominant follicle. The slope of the regression line of the stroma did not change over time.

\section{Correlations between hormone content and echotexture of follicles}

The pixel heterogeneity of images of the antrum and wall, respectively, were correlated with the concentration of oestradiol $(r=-0.53$ and $r=-0.48 ; P<0.001)$ and the ratio of oestradiol:progesterone $(r=-0.54$ and $r=-0.53 ; P<0.001)$ in follicular fluid. The slope of the regression line of pixel values across the follicle wall was correlated with concentrations of progesterone $(r=0.46 ; P<0.001)$, oestradiol $(r=-0.57$; $P<0.001)$, and the ratio of oestradiol:progesterone $(r=-0.62$; $P<0.001)$ in follicular fluid.

\section{Discussion}

The results of the present study support the hypothesis that echotexture characteristics of high-resolution images of the follicle antrum and wall are correlated with the functional and endocrine status of the follicle. The unique design of the present study was intended to permit evaluation of follicles specifically with respect to status (pre- versus post-selection, and dominant versus subordinate), phase (growing, static and regressing) and wave of origin (first, second and ovulatory waves). Status- and phase-specific changes in pixel values and slope of the follicle wall, and the pixel heterogeneity of the follicle antrum and wall were documented. Specific correlations were discovered between the hormone content of follicular fluid (oestradiol, oestradiol:progesterone ratio) and echotexture 


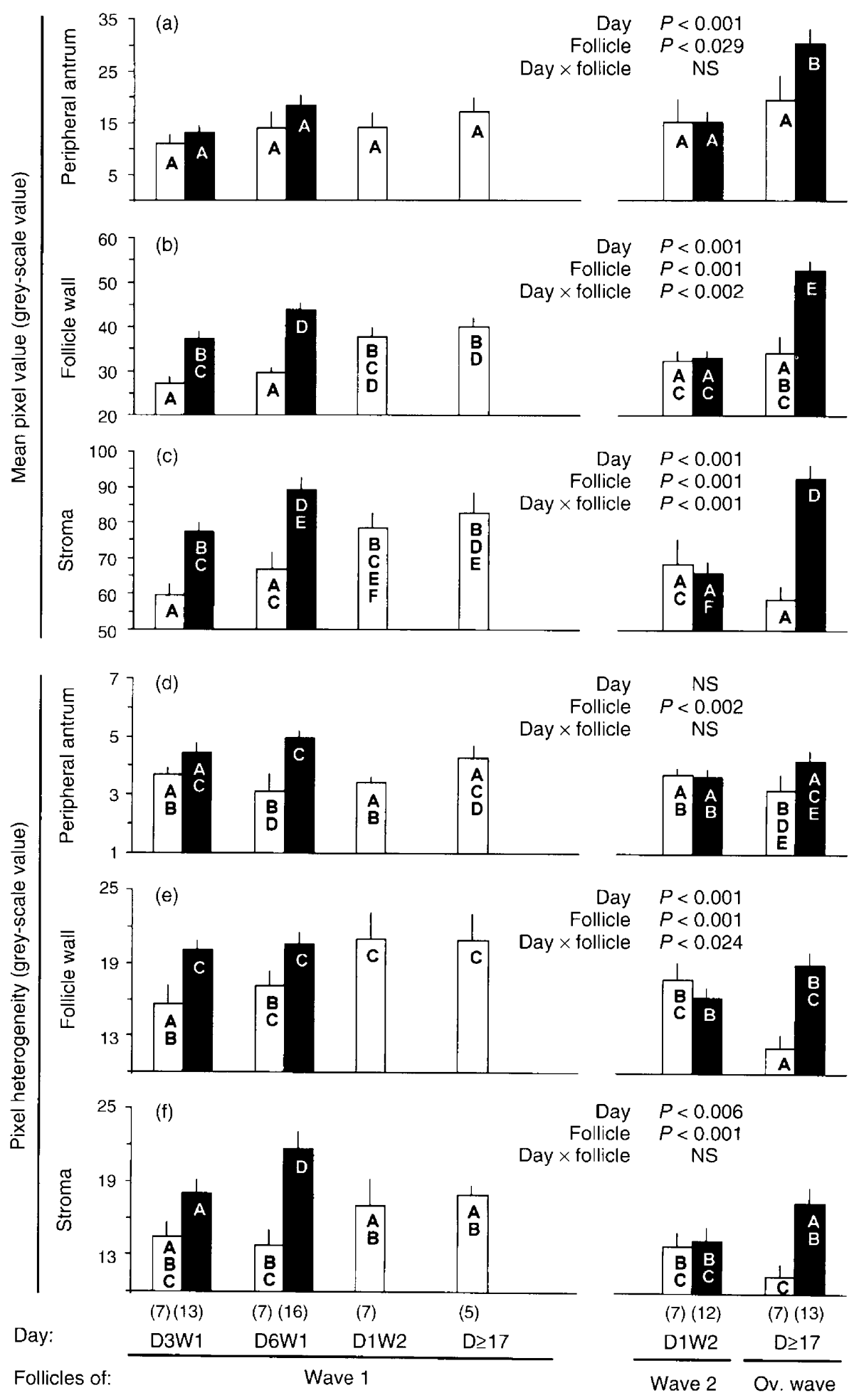

Fig. 5. Mean $\pm \operatorname{SEM}(a, b, c)$ pixel value and $(d, e, f)$ pixel heterogeneity obtained by line-analysis of the peripheral antrum $(a, d)$, follicle wall $(b, e)$ and stroma $(c, f)$ of the dominant $(\square)$ and subordinate (ם) follicles at different stages of wave development (D3W1: day 3 of wave 1; D6W1: day 6 of wave 1 ; DIW2: day 1 of wave $2 ; \mathrm{D} \geq 17$ : during pro-oestrus $\geq 17$ days after ovulation; $O v$. wave: ovulatory wave). Numbers in parentheses below the $x$-axis indicate the number of follicles analysed for each follicle type. Bars with no common letters indicate significantly different values $(P<0.05)$. NS, not significant. 


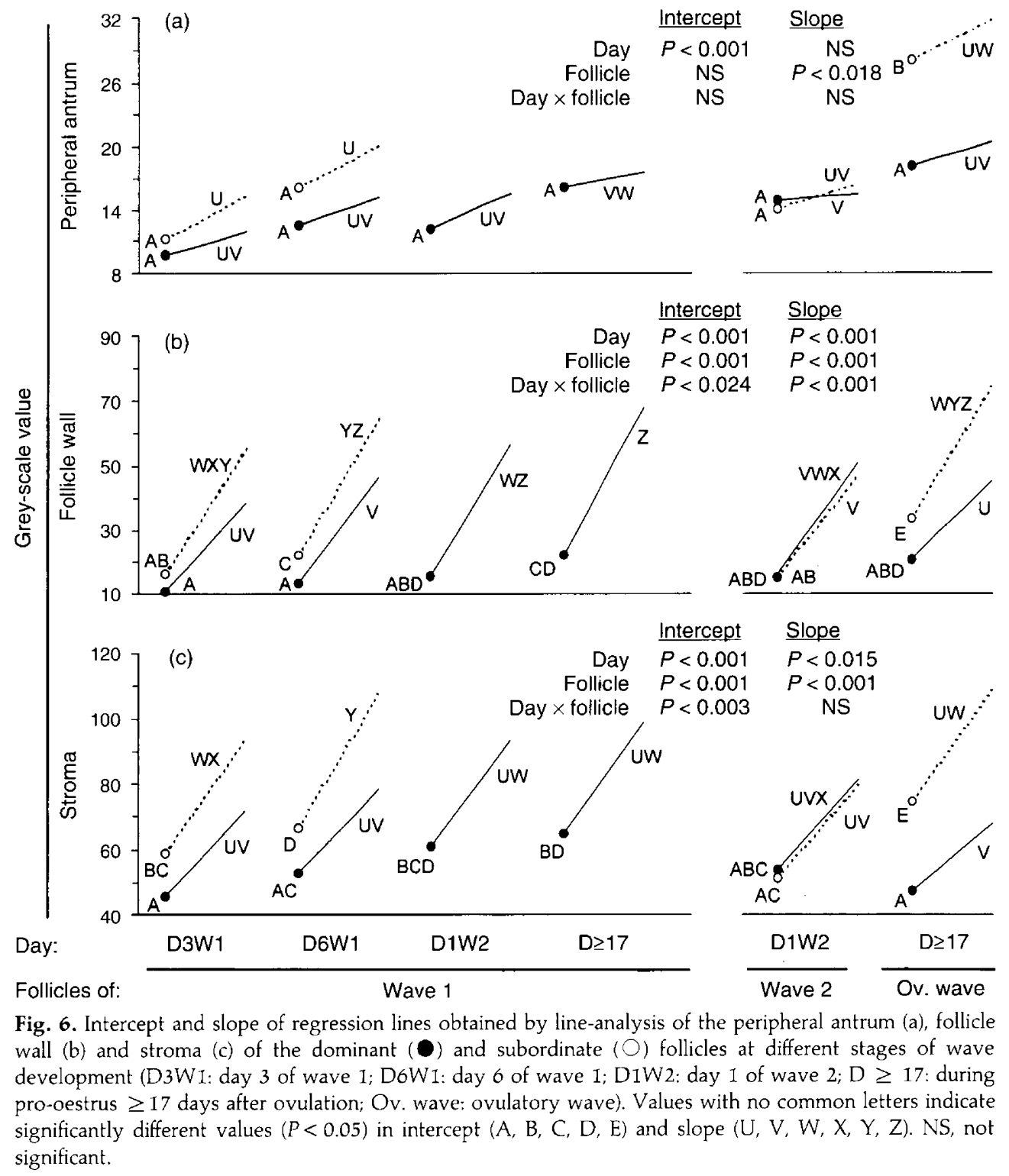

characteristics (pixel heterogeneity of follicle antrum and wall, slope of regression line).

The identification of follicle status (dominant versus subordinate, and growing, static or regressing) requires evaluation of serial ultrasound examinations and is accomplished only in retrospect. To date, there is no method to identify the physiological status of a follicle on the basis of a single ultrasound examination. Computer-assisted quantitative echotexture analysis offers the potential of such a highly sensitive and quantitative method of assessing follicular and luteal status (Pierson and Adams, 1995; Singh et al., 1997). Pixel values of ultrasound images of the bovine corpus luteum (Singh $e t$ al, 1997) were highly correlated with plasma and luteal tissue progesterone concentrations and morphometric characteristics.

Mean pixel value, obtained by spot analysis of the antrum, is a measure of the overall (average) grey-scale value of the pixels falling under the measuring circle, while pixel heterogeneity of the antrum is a measure of the variation in grey-scale value of pixels falling under the measuring circle. During the late-static and regressing phases of the dominant and subordinate follicle, granulosa cells are sloughed into the antrum as sheets or individually (Singh, 1997). It is likely that these cells or their degeneration products were responsible for the observed increase in pixel heterogeneity of the follicle antrum and for the higher mean pixel value near the wall versus near the centre of the antrum. The present observations are in complete agreement with our earlier studies (Pierson and Adams, 1995; Tom, 1996), in which significant increases in mean pixel value and pixel heterogeneity of the antrum were detected during the late-static and regressing phases of anovulatory dominant follicles.

The changes in follicle echotexture observed in the present study were coincident with changes in ovulatory potential or functional dominance of the follicle reported previously. It has been proposed that functional alterations of the dominant 
follicle occur sometime during the mid- to late-static phase of development (Ginther et al, 1989a, b; Kastelic ef al., 1990; Fortune et al., 1991; Ko et al., 199I; Adams et al., 1993a, b; Guilbault et al., 1993). The emergence of a new wave (Adams et al., 1993a, b; Fortune, 1993) and major changes in oestradiol content of follicular fluid (Badinga et al., 1992; Price et al., 1995), similar to those observed in the present study, have been considered as other indicators of viability or functional dominance of the follicle. Line analysis of the area close to the follicle wall was partitioned into three segments to represent morphologically distinct parts of the follicle comprising mainly (although not exclusively) the peripheral portion of the antrum, the follicle wall proper, and the stroma. Structurally, the theca interna (more cellular part) gradually merges into the stroma (more fibrous part) without any abrupt interface. This change is reflected in ultrasound images as a gradual increase in pixel value from the beginning of the follicle wall to the end at the stroma. The slope of the regression line of each region is an indicator of relative change in grey-scale value of successive pixels from the beginning to the end of a particular segment. The pixel heterogeneity of the follicle wall increased and the slope of the line became steeper during the regressing phase of the dominant follicle. Increases in the antral and wall pixel heterogeneity, as well as increases in mean pixel value and regression line slope of the wall, were observed in late-static dominant follicles of wave 1 . The echotexture characteristics of the early-static dominant follicle were intermediate between the growing and late-static phase follicles. In general, regressing follicles with a thinner wall resulted in a steeper slope value for the follicle wall segment and in a higher intercept (beginning point) value for the stroma segment. As expected, the slope of the stroma did not change over time.

There are also structural differences between follicles of different status (Singh, 1997) and these differences correlate well with the echotexture analysis of the follicle wall. The preovulatory follicle had the thickest wall, the lowest cell density in the granulosa and theca layers, and the highest vascularity and oedema in the theca interna (Singh, 1997). All of these characteristics are associated with the lowest pixel heterogeneity value and the lowest regression line slope value. The present results are concordant with earlier observations that the ultrasound image of the wall of anovulatory dominant bovine follicles at the end of the growing phase, and preovulatory follicles of cattle and humans (Martinuk et al., 1992; Adams and Pierson, 1995; Tom, 1996), appears darker than that of atretic follicles.

Significant correlations were discovered between the endocrine status (progesterone, oestradiol, and oestradiol:progestrone ratio) and echotexture measures of variation of the follicle wall (pixel heterogeneity and slope of the regression line). Although correlation values were relatively low, they were highly significant. These temporal relationships could have far reaching implications in the field of medical imaging because it may become possible to assess individual follicle function and health using such non-invasive techniques.

Consistent with earlier results (Badinga et al., 1992; Guilbault et al., 1993; Price et al., 1995; Carriere et al., 1996; Stewart et al., 1996), maximal amounts of oestradiol in the growing dominant follicles were followed by a threefold decrease by the end of the growing phase (early-static phase, D6W1). A further several-fold decrease was recorded between the early- (D6W1) and late-static (DIW2) phases. In the present study, the follicular content of progesterone did not differ among the growing, early-static and late-static dominant follicles; it was only the regressing follicles (both dominant and subordinate) that contained significantly higher amounts of progesterone. The results of the present study confirm the earlier suggestion (Price et al., 1995) that growing dominant follicles contain high oestradiol and low progesterone and that, as the growth rate slows, oestradiol concentration decreases. The ratio of oestradiol:progesterone was influenced mainly by marked changes in oestradiol concentration in the follicular fluid; the concentration of oestradiol was highly correlated with the oestradiol:progesterone ratio.

The oestradiol:androstenedione ratio changed markedly between the growing and early-static phases of the dominant follicle of wave 1. Although early-static dominant follicles of wave 1 produced lower amounts of oestradiol than the growing dominant follicle, the oestradiol:androstenedione ratio was higher in the early-static dominant follicle because of a near depletion of androstenedione. This observation is consistent with the earlier suggestion that the rate-limiting step in steroidogenesis in dominant bovine follicles may be the availability of androgens rather than cytochrome $\mathrm{P}_{450}$ aromatase (Badinga et al., 1992; Xu et al., 1995). This situation may not be strictly true for subordinate follicles, in which more androstenedione than oestradiol was present in the follicular fluid (in general, oestradiol:androstenedione was < 1). Only the follicular fluid of growing dominant follicles of wave $I$ and preovulatory follicles contained more androstenedione than progesterone, and these two types of follicle also produced markedly more oestradiol than all the other follicles.

In summary, echotexture analysis of images of ovarian follicles exhibited phase-specific changes related to changes in steroid hormone concentrations in follicular fluid. The mean pixel value and heterogeneity of the antrum and wall were characteristically low in preovulatory dominant follicles as well as in growing and early-static phase anovulatory dominant follicles. Conversely, pixel heterogeneity was characteristically high in late-static and regressing phase dominant follicles and in mid-static to regressing phase subordinate follicles. The slope of the pixel value line spanning the follicle wall increased progressively from the growing to the regressing phase (corresponding to a progressive thinning of the follicle wall); the preovulatory dominant follicle had the thickest wall and the lowest slope. Specific correlations were discovered between the hormone (oestradiol and oestradiol:progesterone ratio) content of follicular fluid and echotexture characteristics. It was concluded that quantitative changes in the echotexture of ultrasound images occur concurrent with changes in functional and endocrine characteristics of the bovine follicles and that computer-assisted echotexture analysis may be developed into a robust diagnostic and prognostic tool to assess the physiological or pathological status of ovarian follicles.

This project was supported by grants from the Natural Sciences and Engineering Research Council of Canada and the Medical Research Council of Canada. J. Singh is supported by a Canadian Commonwealth Scholarship. The authors thank C. Becker, J. Deptuch, K. Lightfoot and J. Tom for technical help. 


\section{References}

Adams GP and Pierson RA (1995) Bovine model for the study of follicular dynamics in humans Theriogenology 43 113-120

Adams GP, Matteri RL, Kastelic JP, Ko JCH and Ginther OJ (1992) Association between surges of follicle-stimulating hormone and the emergence of follicular waves in heifers Journal of Reproduction and Fertility 94 177-188

Adams GP, Kot K and Ginther OJ (1993a) Selection of a dominant follicle and suppression of follicular growth in heifers Animal Reproduction Science 30 259-271

Adams GP, Kot K, Smith CA and Ginther OJ (1993b) Effect of the dominant follicle on regression of its subordinates in heifers Canadian Journal of Animal Science $73 \quad 267-275$

Badinga L, Driancourt MA, Savio JD, Wolfenson D, Drost M, de la Sota RL and Thatcher WW (1992) Endocrine and ovarian responses associated with the first-wave dominant follicle in cattle Biology of Reproduction 47 871-883

Carriere PD, Harvey D and Cooke GM (1996) The role of pregnenolonemetabolizing enzymes in the regulation of oestradiol biosynthesis during development of the first wave dominant follicle in the cow Journal of Endocrinology $149233-242$

Choudary JB, Gier HT and Marion GB (1968) Cyclic changes in bovine vesicular follicles Joumal of Animal Science 27 468-471

Ferrandi B, Cremonesti F, Gieger R, Consiglio AL, Carnevali A and Porcelli F (1993) Quantitative cytochemical study of some enzymatic activities in preovulatory bovine oocytes after in vitro maturation Acta Histochemica (Jena) 95 89-96

Fortune JE (1993) Follicular dynamics during the bovine oestrous cycle: a limiting factor in improvement of fertility Journal of Reproduction Science 33 111-125

Fortune JE, Sirois J, Turzillo AM and Lavoir M (1991) Follicle selection in domestic ruminants Journal of Reproduction and Fertility Supplement $\mathbf{4 3}$ 187-198

Fritz P, Hoenes J, Lutz D, Multhaupt H, Mischinski A, Dorrer R, Schwarzmann P, Tuczek HV and Muller W (1989) Quantitative immunohistochemistry: standardization and possible application in research and surgical pathology Acta Histochemica (Jena) Supplement XXXVII 213-219

Fritz P, Multhaupt H, Hoenes J, Lutz D, Doerrer R, Schwarzmann P and Tuczek HV (1992) Quantitative histochemistry Progress in Histochemistry and Cytochemistry 24 1-57

Ginther OJ (1995) Ultrasonic Imaging and Animal Reproduction: Fundamentals Book 1 pp 7-82, 147-155, Equiservices Publishing, Cross Plains, WI

Ginther OJ, Kastelic JP and Knopf L (1989a) Composition and characteristics of follicular waves during the bovine oestrous cycle Animal Reproduction Science $20187-200$

Ginther OJ, Kastelic JP and Knopf L (1989b) Intraovarian relationship among dominant and subordinate follicles and corpus luteum in heifers Theriogenology 32 787-795

Ginther OJ, Knopf L and Kastelic JP (1989c) Temporal associations among ovarian events in cattle during oestrous cycles with two and three follicular waves Journal of Reproduction and Fertility 87 223-230

Guilbault LA, Rouillier P, Matton P, Glencross RG, Beard AJ and Knight PG (1993) Relationships between the levels of atresia and inhibin contents ( $\alpha$ subunit and $\alpha-\beta$ dimer) in morphologically dominant follicles during their growing and regressing phases of development in cattle Biology of Reproduction 48 268-276

Hassett LJ and Sloss V (1984) The use of clenbuterol to produce relaxation of the myometrium during caesarean operation in cattle Australian Veterinary Journal $61401-403$

Heller M and Jehle D (1995) Ultrasound in Emergency Medicine pp 1-40 WB Saunders Company, Philadelphia

Hudson RS (1986) Genital surgery of the cow. In Current Therapy in Theriogenology (2nd Edn) pp 341-352 Ed. DA Morrow. WB Saunders Company, Toronto

Ireland JJ and Roche JF (1983) Development of nonovulatory antral follicles in heifers: changes in steroids in follicular fluid and receptors for gonadotropins Endocrinology 112 150-156

Kastelic JP, Knopf L and Ginther OJ (1990) Effect of day of prostaglandin $F_{2 n}$ treatment on selection and development of the ovulatory follicle in heifers Animal Reproduction Science 23 169-180
Knopf L, Kastelic JP, Schallenberger E and Ginther OJ (1989) Ovarian follicular dynamics in heifers. Test of a two-wave hypothesis by ultrasonically monitoring individual follicles Domestic Animal Endocrinology 6 $111-119$

Ko JCH, Kastelic JP, Del Campo MR and Ginther OJ (1991) Effects of a dominant follicle on ovarian follicular dynamics during the oestrous cycle in heifers Journal of Reproduction and Fertility $91511-519$

Kremkau FW (1989) Diagnostic Ultrasound: Principles, Instruments, and Exercises (3rd Edn) pp 1-50, 147-176, 219-231, WB Saunders Company, Philadelphia

Martinuk SD, Chizen DR and Pierson RA (1992) Ultrasonographic morphology of the human preovulatory follicle wall prior to ovulation Clinical Anatomy 5 1-14

Pierson RA and Adams GP (1995) Computer-assisted image analysis, diagnostic ultrasonography and ovulation induction: strange bedfellows Theriogenology 43 105-112

Pierson RA and Ginther OJ (1986) Ovarian follicular populations during early pregnancy in heifers Theriogenology $26649-659$

Pierson RA and Ginther OJ (1987a) Follicular populations during the estrous cycle in heifers I. Influence of day Animal Reproduction Science 14 165176

Pierson RA and Ginther OJ (1987b) Ultrasonographic appearance of the bovine uterus during the estrous cycle Journal of the American Veterinary Medical Association 190 995-1001

Pierson RA and Ginther OJ (1988) Follicular populations during the estrous cycle in heifers III. Time of selection of ovulatory follicle Animal Reproduction Science 16 81-95

Price CA, Carrière PD, Bhatia B and Groome NP (1995) Comparison of hormonal and histological changes during follicular growth, as measured by ultrasonography, in cattle Journal of Reproduction and Fertility $10363-$ 68

Renucci RP, Feuerstein C, Manier M, Lorimier P, Savasta M and Thibault J (1991) Quantitative image analysis with densitometry for immunohistochemistry and autoradiography of receptor binding sites - methodological considerations Journal of Neuroscience Research 28 583-600

Savio JD, Keenan L, Boland MP and Roche JF (1988) Pattern of growth of dominant follicles during the oestrous cycle in heifers Journal of Reproduction and Fertility 83 663-671

Savio JD, Boland MP, Hynes N, Mattiacci MR and Roche JF (1990) Will the first dominant follicle of the estrous cycle of heifers ovulate following luteolysis on day 7 ? Theriogenology 33 677-687

Singh J (1997) Bovine Ovary: Morphological and Biochemical Kinetics PhD Thesis, University of Saskatchewan, Saskatoon

Singh J, Pierson RA and Adams GP (1997) Ultrasound image attributes of the bovine corpus luteum: structural and functional correlates Journal of Reproduction and Fertility 109 35-44

Sirois J and Fortune JE (1988) Ovarian follicular dynamics during the estrous cycle in heifers monitored by real time ultrasonography Biology of Reproduction 39 308-317

Sternberger LA and Sternberger NH (1986) The unlabeled antibody method: comparison of peroxidase-antiperoxidase with avidin-biotin complex by a new method of quantification Journal of Histochernistry and Cytochemistry 34 599-605

Stewart RE, Spicer LJ, Hamilton TD, Keefer BE, Dawson LJ, Morgan GL and Echternkamp SE (1996) Levels of insulin-like growth factor (IGF) binding proteins, luteinizing hormone and IGF-I receptors, and steroids in dominant follicles during the first follicular wave in cattle exhibiting regular estrous cycles Endocrinology $1372842-2850$

Sunderland SJ, Knight PG, Boland MP, Roche JF and Ireland JJ (1996) Alterations in intrafollicular levels of different molecular mass forms of inhibin during development of follicular- and luteal-phase dominant follicles in heifers Biology of Reproduction 54 453-462

Tom JW (1996) Echotexture Analysis of the Bovine Ovary MSc Thesis, University of Saskatchewan, Saskatoon

Xu Z, Garverick HA, Smith GW, Micheal FS Hamilton SA and Youngquist RS (1995) Expression of messenger RNA encoding cytochrome $P_{450}$ side-chain cleavage, cytochrome $\mathrm{P}_{450} 17 \alpha$-hydroxylase, and cytochrome $\mathrm{P}_{450}$ aromatase in bovine follicles during the first follicular wave Endocrinology 136 981-989 